\title{
Identity Avoidance and Rendaku*
}

\author{
Shigeto Kawahara ${ }^{\mathrm{a}}$ and Shin-ichiro Sano ${ }^{\mathrm{b}}$ \\ ${ }^{a}$ Keio University and ${ }^{b}$ Okayama Prefectural University
}

\section{Introduction}

1.1 Synopsis One important observation that is made in the past phonological research is that constraints on output structures can both block and trigger phonological processes (i.e., conspiracy: Kisseberth 1970). This paper reports an experiment which shows that an Identity Avoidance constraint (a.k.a. the OCP) both blocks and triggers one phonological process in the same language, namely rendaku in Japanese. Our wugexperiment shows that rendaku is more likely to apply when the two CV moras across a morpheme boundary are identical; i.e. an Identity Avoidance constraint triggers rendaku. The experiment also shows that rendaku is less likely to apply when it would result in two adjacent identical CV moras across a morpheme boundary; i.e. the Identity Avoidance constraint blocks rendaku. These blocking and triggering effects of the general Identity Avoidance constraint on rendaku are a new discovery in Japanese phonology, despite the fact that rendaku has been studied extensively in the previous literature, suggesting the importance of experimentation in phonological research. Moreover, our case study offers experimental confirmation of the OCP conspiracy in natural languages.

1.2 Theoretical background One important observation that has been made in the phonological research in the last 40 years or so is that constraints on output structures can both block and trigger phonological processes, an observation known as "conspiracies" (Kisseberth 1970 et seq.). ${ }^{1}$ Kisseberth (1970) shows that in Yawelmani the constraint against triconsonantal clusters (*CCC) blocks vowel syncope, and the same constraint triggers the vowel epenthesis rule at the same time.

The Obligatory Contour Principle (the OCP: Leben 1973), which prohibits adjacent identical segments or features, is another prime example. McCarthy (1986) argued that the OCP can block otherwise productive syncope processes in various languages, including Afar and Tonkawa. Building on this work, Yip (1988) further claimed that the OCP can trigger phonological processes in order to avoid adjacent identical segments or features; e.g. dissimilation in Cantonese. This dual nature of output constraints in phonology-the blockage effect and triggering effect-is hard to capture in rule-based theories of phonology (Kisseberth, 1970; McCarthy, 2002). The blocking effect would be "buried" in the structural description of a phonological rule, and the trigger effect is impossible to state in purely rule-based theories (McCarthy, 2002).

The dual nature of output constraints thus contributed to the birth and development of constraint-based theories, most notably Optimality Theory (Prince \& Smolensky, 1993/2004) (see also Goldsmith 1994; Legendre et al. 1990; Paradis 1988 for other phonological theories that incorporate constraints). This paper reports an experiment which further supports these constraint-based theories of phonology by showing that

\footnotetext{
* This experiment is a part of a larger project to test aspects of rendaku by way of experimentation (Sano \& Kawahara, 2013). See Kawahara (to appear) for a summary of previous experimental approaches to rendaku. We would like to thank the members of the Keio phonetics/phonology study group (Donna Erickson, Haruka Fukazawa, Hinako Masuda, Yuriko Matsumoto, Jeff Moore, Yoko Sugioka, and Yukiko Sugiyama) as well as the participants of Tokyo Circle of Phonologists in October 2012 (University of Tokyo) and Phonology 2013 in November 2013 (UMass, Amherst) for their comments. We are particularly grateful to Mark Irwin for sharing his recent research with us. Also, thanks are due to Sarah Korostoff. Jeff Moore, and Jess Trombetta for proofreading drafts of this paper. This work is supported by Japan Society for the Promotion of Science (JSPS) KAKENHI Grant \#25770157 and \#25280482 to the second author. Remaining errors are ours.

1 McCarthy (2002) provides a list of references on conspiracies as well as those on the role of output constraints in phonology (pp.62-63), which we do not reproduce here. A related notion is "homogeneity of target" in which the same target can be avoided by various types of phonological patterns across different languages (Casali, 1996; McCarthy, 2002; Pater, 1999; Zuraw \& Lu, 2009).
}

(c) 2014 Shigeto Kawahara ${ }^{\mathrm{a}}$ and Shin-ichiro Sano ${ }^{\mathrm{b}}$

Proceedings of Phonology 2013

Completed Dec, 2013 
an identity avoidance constraint both blocks and triggers one phonological process in the same language, namely rendaku in Japanese. The paper in short offers an experimental confirmation of the conspiracy due to the identity avoidance constraint.

1.3 Empirical background: rendaku in Japanese Rendaku in Japanese is a morphophonological process where the initial consonant of the second member of compounds becomes voiced, as in (1): ${ }^{2}$

(1) Rendaku: Voicing of initial consonants
a. /oo+tako/ $\rightarrow$ [oo+dako] 'big octopus'
b. /yo+sakura/ $\rightarrow$ [yo+zakura] 'night cherry'
c. /oo+karasu/ $\rightarrow$ [oo+garasu] 'big crow'
d. /hi+hasira/ $\rightarrow$ [hi+basira] 'fire pillar'

However, not all compounds undergo this voicing process. Many studies, both within the Japanese traditional grammar and within the generative tradition, have shown that many factors-phonological, morphological, lexical, and even arguably syntactic—affect the likelihood of rendaku application (e.g. Itô \& Mester 1986, 2003; Kindaichi 1976; Kubozono 2005; Okumura 1984; Sugioka 2002, 2005; Vance to appear-see Irwin to appear for an extended list of bibliography). One famous example is Lyman's Law, where rendaku is blocked when the second member of a compound already contains a voiced obstruent, as in (2) (Itô \& Mester, 1986, 2003; Kawahara, 2012; Lyman, 1894; Vance, 2007, to appear):

(2) Blockage of rendaku due to Lyman's Law
a. /oo+tokage/ $\rightarrow$ [oo+tokage], *[oo+dokage] 'big lizard'
b. /oo+sazi/ $\rightarrow$ [oo+sazi], *[oo+zazi] 'big spoon'
c. /yama+kazi/ $\rightarrow$ [yama+kazi], *[yama+gazi] 'mountain fire'
d. /kata+hizi/ $\rightarrow$ [kata+hizi], *[kata+bizi] 'one elbow'

Itô \& Mester (1986) proposed that this blockage effect can be captured as resulting from the effect of the OCP constraint on the [+voice] feature (on obstruents).

1.4 The current study Our nonce-word experiment tested another kind of the OCP effect on the applicability of rendaku, namely avoidance of two adjacent identical CV moras in Japanese phonology (henceforth Identity Avoidance: Yip 1995, 1998). ${ }^{3}$ The motivation of this study comes from an independent observation about recent phonological changes in Japanese verbal conjugations. Sano (2013) has studied two recent sound changes in Japanese phonology: [ra]-deletion where [ra] is dropped from the potential suffix [-rare] (Inoue, 1998; Itô \& Mester, 2004) and [sa]-insertion where the causative suffix looks like it shows an additional [sa] sequence. ${ }^{4}$ By analyzing the Corpus of Spotaneous Japanese (the CSJ: Kokuritsu-KokugoKenkyuujo 2008), one of the largest corpus of spoken Japanese, he found that [ra]-deletion is much less likely to apply when it results in an identical CV mora sequence (compare (3a) and (3b)).

$2 / \mathrm{h} /$ becomes [b] when it becomes voiced due to rendaku. This alternation stems from the fact that $/ \mathrm{h} /$ used to be [p] in old Japanese (Ueda, 1898); this /h/-[p] relationship may arguably hold as an underlying-surface representation relationship in the synchronic phonology of Japanese as well (McCawley, 1968).

One may also question the phonological status of rendaku-it may instead be a lexicalized pattern, in which native speakers remember how likely rendaku happens for each lexical item (Ohno 2000; see Kawahara to appear for discussion). If this lexicalist view is correct, then we should not use rendaku for phonological argumentation. However, in this paper, we take rendaku to be a (morpho)phonological process (or at least there is a phonological aspect to it), because (i) it applies to nonce words as we will see in the current experiment (as well as in other previous experimental studies on rendaku), and (ii) it is subject to a phonological constraint (here, an identity avoidance constraint). See Fukuda \& Fukuda (1994) and Kobayashi et al. (2013) for other experimental evidence that rendaku has a phonological—i.e. grammatical rather than lexical or analogical—aspect.

$3 \mathrm{CV}$ sequences are likely to constitute a phonological unit in Japanese, and some theories of Japanese prosody group them as one mora (e.g. Itô 1989; Kubozono 1989; Labrune 2012).

4 Technically, [as] is inserted before the potential suffix [-ase], but on the surface, it looks as if an extra [sa] is inserted. 
(3)

[ra]-deletion and its blockage

a. [kari-rare-ru] $\rightarrow$ [kari-re-ru] 'can borrow'

b. [ire-rare-ru] $\rightarrow$ ?[ire-re-ru] 'can insert'

Similarly, [sa]-insertion is categorically prohibited when it results in an identical CV mora (compare (4a) and (4b)).

(4) [sa]-insertion and its blockage

a. [ik-ase-ru] $\rightarrow$ [ik-asase-ru] 'make somebody go'

b. [tobas-ase-ru] $\rightarrow *$ [tobas-asase-ru] 'make somebody fly'

Based on these pieces of evidence, Sano (2013) has argued that Japanese avoids sequences of two identical CV moras. This effect of Identity Avoidance can be viewed as an effect of the OCP on two adjacent $\mathrm{CV}$ moras, i.e., OCP(MORA). The research question that we address in this study is thus whether this sort of Identity Avoidance affects the application of rendaku or not.

Although rendaku has been quite extensively studied in the literature, there is very little research on the effect of Identity Avoidance of rendaku. Labrune (2012) and Sato (1988) hint at the role of Identity Avoidance on the blockage of rendaku (but not the trigger effect), although Irwin (2013) denies their claim based on statistical evidence in the lexicon. Our experiment settles this debate through an experiment by showing that Identity Avoidance both blocks and triggers rendaku, at least in an experimental setting.

In short, building on the observation by Sano (2013) and considering the debate mentioned above, we tested whether the Identity Avoidance constraint affects the applicability of rendaku. Furthermore, going beyond merely testing an aspect of one phonological rule in Japanese phonology, rendaku provides a nice ground to experimentally test the dual nature of phonological constraints, which was reviewed in section 1.2. We can test whether rendaku can be blocked by Identity Avoidance, and at the same time test whether rendaku can be triggered by the same constraint.

To preview the results, the current study shows that rendaku is more likely to apply when the two CV moras across a morpheme boundary are identical; that is, the Identity Avoidance constraint (i.e. ${ }^{*}\left[\mathrm{CV}_{i}+\mathrm{CV}_{i}\right]$ ) triggers rendaku. The experiment also shows that rendaku is less likely to apply when it would result in two adjacent identical consonants across a morpheme boundary (i.e. $/ \mathrm{CV}_{i}+\mathrm{CV}_{k} / \rightarrow *\left[\mathrm{CV}_{i}+\mathrm{CV}_{i}\right]$ ); the identity avoidance constraint blocks rendaku.

\section{Method}

2.1 Task The current experiment used forced-choice wug-tests (Berko, 1958) to examine the effect of Identity Avoidance on rendaku. The participants were given a real noun as a first noun (N1) and a nonce noun as a second noun (N2), and were asked to choose the best resulting compounding form. ${ }^{5}$ For example, they were asked: "given [ika] 'squid' and [kaniro] (nonce), what would be the better outcome, [ikakaniro] or [ikaganiro]? Please choose the one that sounds like the more natural outcome for you."

2.2 Stimuli The stimuli consisted of two sets: Set 1 tested the effect of Identity Avoidance on triggering rendaku; Set 2 tested the effect of Identity Avoidance on blocking rendaku.

The experimental items for Set 1 are provided in Table 1. In Set 1, in one condition, the two CV moras across the morpheme boundary were identical (e.g. [ika]+[kaniro]), whereas in the other condition they were not identical (e.g. [ika]+[saniro]). Set 1 and Set 2 used the same set of second nouns (=N2), with all the consonants that can potentially undergo rendaku ([t, k, s, h]) (see (1) and also Kawahara 2012). Three different nonce words were created for each type of the four consonants, while controlling for the quality of the last two syllables. Each set also included 4 types of first nouns $(=\mathrm{N} 1)$, where one of the four nouns ended with a CV mora that is identical to the initial mora of some N2. Therefore, each block included 48 test items (4 N1* 4 consonants * 3 lexical items). All the factorial combinations of N1 and N2 are tested.

\footnotetext{
5 Our previous (pilot) experiments showed that using nonce nouns for both $\mathrm{N} 1$ and N2 can impose too much psycholinguistic burden on naive native speakers during wug tests about rendaku. Therefore, real words were used for N1. Most previous experimental studies of rendaku used real words either for N1 or N2 (Kawahara, to appear).
} 
Table 1: The list of the stimuli used in Set 1. All combinations of N1 and N2 $(4 * 12=48)$ were tested. The gloss for N1: [ika] 'squid'; [kusa] 'grass'; [kata] 'half'; [naha] 'Naha (place name)'. N2s are nonce words.

\begin{tabular}{|c|c|c|c|c|}
\hline N1 & & $\mathrm{N} 2$ & & \\
\hline [ika] & * & [kaniro] & [kamoke] & [kahusa] \\
\hline [kusa] & & [saniro] & [samoke] & [sahusa] \\
\hline [kata] & & [taniro] & [tamoke] & [tahusa] \\
\hline [naha] & & [haniro] & [hamoke] & [hahusa] \\
\hline
\end{tabular}

The list of stimuli for Set 2 is shown in Table 2. In Set 2, in one condition, the two moras across the morpheme boundary were identical except for voicing of the onset consonant (e.g., [iga]+[kaniro]); in this condition, rendaku would result in two adjacent identical CV moras (i.e., [iga+ganiro]). In the other condition, the first obstruent was a voiced stop, but differed in place or manner with the second consonant (e.g., [iga]+[taniro]); rendaku would not result in two identical moras (i.e. [iga+daniro]). In both conditions, N1 contained a voiced obstruent, thereby controlling for a potential effect of the strong version of Lyman's Law (see section 4.2).

Table 2: The list of the stimuli used in Set 2. All combinations of N1 and N2 $(4 * 12=48)$ were tested. The gloss: [iga] 'spiky'; [aza] 'bruised'; [kuda] 'pipe'; [kaba] 'hippopotamus'. N2s are nonce words.

\begin{tabular}{|c|c|c|c|c|}
\hline N1 & & $\mathrm{N} 2$ & & \\
\hline [iga] & * & [kaniro] & [kamoke] & [kahusa] \\
\hline [aza] & & [saniro] & [samoke] & [sahusa] \\
\hline [kuda] & & [taniro] & [tamoke] & [tahusa] \\
\hline [kaba] & & [haniro] & [hamoke] & [hahusa] \\
\hline
\end{tabular}

2.3 Procedure and participants The experiment was run online using Surveymonkey. The participants were first told what rendaku is, and then were asked to go through three practice questions using [nise] 'fake' as N1 and real words as N2 in order to familiarize themselves with rendaku and the task of the current experiment. The stimuli for Set 1 were blocked and ordered before the stimuli for Set 2 . The two blocks were separated by a self-timed break. The order of the stimuli was randomized per participant by Surveymonkey within each block. There were no time limits for answering questions. Thirty-nine native speakers of Japanese participated in this study. They participated in the experiment voluntarily, and no monetary compensation was offered. $^{6}$

\section{Results}

Figure 1 shows the probability of rendaku application for Set I (the trigger set), with error bars representing 95\% confidence intervals. The left bar represents the condition in which the two moras across a morpheme boundary were identical, while the second bar represents the condition in which the two moras were not identical. We observe that Japanese speakers applied rendaku more often to avoid two adjacent identical moras (average rendaku response ratios: 0.63 vs. 0.58 ). A logistic linear mixed model analysis with speakers and items as random variables (Jaeger, 2008) shows that this difference is statistically significant $(z=2.04, p<.05)$.

\footnotetext{
6 The participants were largely graduate and undergraduate students in Japanese universities. We thank Toshio Matsuura, Hinako Masuda, Michinao Matsui, Mayuki Matsui, and Hideaki Zamma for their help with distributing this test.
} 


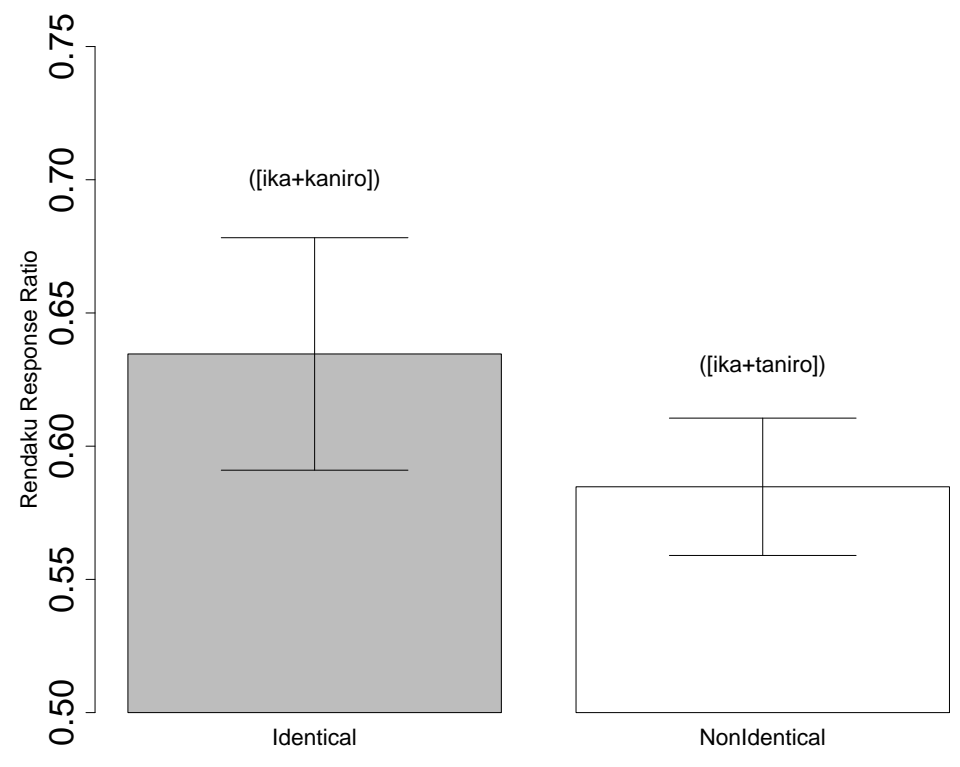

Figure 1: Results of Set 1 (the trigger set). The y-axis represents the rates of rendaku application. The error bars represent $95 \%$ confidence intervals.

Figure 2 shows the results of Set II (the blockage set). The left bar shows the cases in which rendaku would result in two adjacent moras, whereas the right bar shows the cases in which rendaku would not (the average rendaku response ratios: 0.32 vs. 0.47$)$. We observe that rendaku is less likely for cases in which rendaku would result in two identical moras $(z=6.15, p<.001)$. 

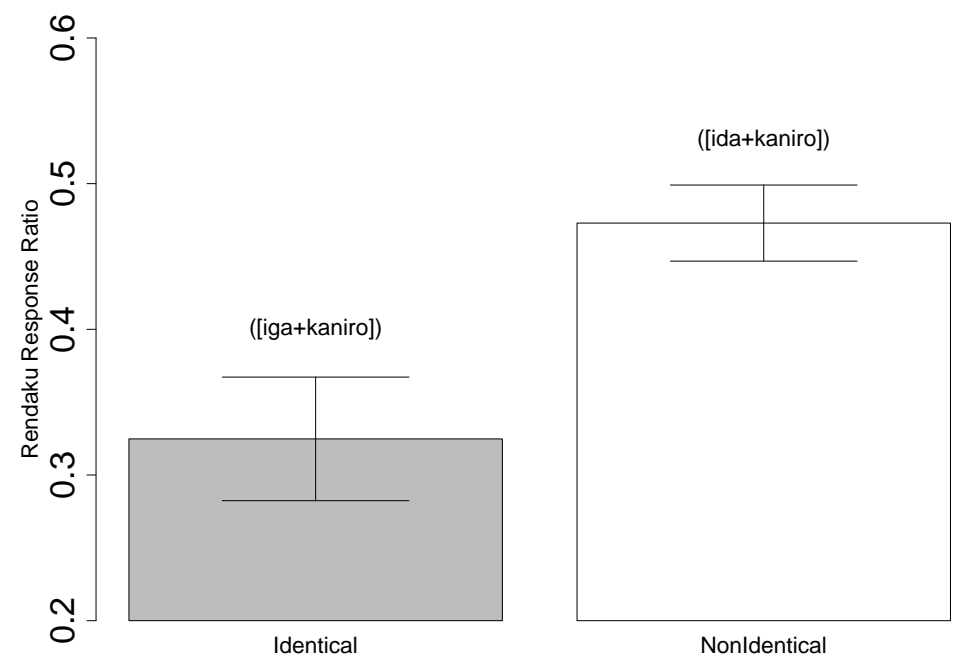

Figure 2: Results of Set 2 (the blockage set). The y-axis represents the rates of rendaku application. The error bars represent $95 \%$ confidence intervals. 


\section{Discussion}

4.1 Discussion of the results Our experiment demonstrates that the Identity Avoidance constraint both triggers (Figure 1) and blocks rendaku (Figure 2) in order to avoid adjacent identical consonants across a morpheme boundary. ${ }^{7}$ The effect of avoidance of two voiced obstruents on rendaku is well known as Lyman's Law (Itô \& Mester, 1986, 2003; Kawahara, 2012; Lyman, 1894; Vance, 2007, to appear), but to the best of our knowledge, this dual effect of the general identity avoidance constraint on rendaku is a new discovery (except that there has been a debate concerning the blockage effect: Irwin 2013; Labrune 2012; Sato 1988).

In addition to this new descriptive discovery in Japanese, this study offers two general implications for phonological theory. One is that the current result constitutes a new case of conspiracy (Kisseberth, 1970). Therefore, it supports the importance of the role of output constraints-in our case, a ban on adjacent identical CV moras-in phonological theory, as emphasized in Optimality Theory (Prince \& Smolensky, 1993/2004) and other constraint-based theories of phonology (Goldsmith, 1994; Legendre et al., 1990; Paradis, 1988). It is difficult—or even impossible - to express the blockage effect in a purely rule-based theory such as SPE (Chomsky \& Halle, 1968), which is the case for the blockage effect on rendaku as well-we would have to posit some kind of output filter (Kisseberth, 1970; McCarthy, 2002). The triggering effect can be encoded as a rendaku-facilitating factor as in (5), but this formulation misses the generalization that it is the output configuration that is avoided-i.e., it cannot explain the dual nature of the identity avoidance constraint. This formulation also misses the generalization found by Sano (2013) that Japanese phonology avoids sequences of identical CV moras in general.

\section{(5) $\quad \mathrm{C}_{i} \rightarrow[+$ voice $] / \mathrm{C}_{i} \mathrm{~V}_{j}+\ldots \mathrm{V}_{j}$ (the probability of rendaku increases in this environment)}

Second, this dual effect of the identity avoidance constraint in rendaku has not been known (except that it was hinted at by Sato 1988 and Labrune 2012, which was disputed by Irwin 2013), despite the fact that rendaku has been studied extensively in the literature, both in the traditional Japanese grammar and in generative phonology (e.g. Irwin to appear; Itô \& Mester 1986, 2003; Kindaichi 1976; Kubozono 2005; Okumura 1984; Vance to appear, among many others). We believe that the reason is that previous approaches have been primarily based on introspection and dictionary evidence. Our project thus highlights the importance of experimentation in linguistic research by showing that an experiment can reveal an aspect of a phonological process which would be otherwise difficult to assess.

4.2 Remaining questions Before closing the paper, there are four remaining questions and issues that we would like to address regarding the current results. First, why was the rendaku response overall lower in the blockage set (Set 2, Figure 2) than in the trigger set (Set 1, Figure 1), as illustrated in Figure 3 ?

One could suspect that the so-called "strong version of Lyman's Law"-which prohibits two voiced obstruents within a word, rather than a stem (Itô \& Mester, 2003; Sugito, 1965; Unger, 1975)—may be at work. N1 always contained a voiced obstruent in Set 2 but never in Set 1, and Japanese speakers may have avoided having two voiced obstruents within the same word (rather than the same morpheme). However, our separate experiment directly testing the effect of the strong version of Lyman's Law did not show a substantial effect on rendaku (Kawahara \& Sano, 2013b; Sano \& Kawahara, 2013). Alternatively, the difference between Set 1 and Set 2 may have arisen from the fact that Set 1 was blocked and ordered before Set 2 in the current experimental setting. This question thus needs to be addressed in a future study.

Another question is why the effect of Identity Avoidance was bigger in the blockage set than in the trigger set (see again Figure 3). It may be that the identical sequences of CV moras are more marked when they involve voiced obstruent onsets than when they involve voiceless obstruent onsets (for example, [...ga+ga...] in Set 2 is more marked than [...ka+ka...] in Set 1-recall that in Set 2, the results of rendaku that violated Identity Avoidance involved two sequences of CV moras with voiced obstruent onsets, whereas Set 1 involved two sequences of $\mathrm{CV}$ moras with voiceless onsets. ${ }^{8}$ Although this hypothesis seems plausible, it again has to be tested in a separate study.

\footnotetext{
7 For how Identity Avoidance interacts with Lyman's Law, see Kawahara \& Sano (2013a). That experiment shows that the blockage of rendaku due to Lyman's Law in nonce words becomes stronger, when it results in two adjacent CV moras (e.g. $/ \mathrm{X}+$ tadanu $/ \rightarrow[\mathrm{X}+$ dadanu $]$ is worse than $/ \mathrm{X}+$ taguta/ $\rightarrow[\mathrm{X}+$ daguta $]$ ).

8 This postulation may follow from Universal Conjoined Constraint Ranking Hypothesis (UCCRH) (Itô \& Mester, 2003; Spaelti, 1997), to the extent that Identity Avoidance is expressed as a conjoined constraint and that voiced
} 

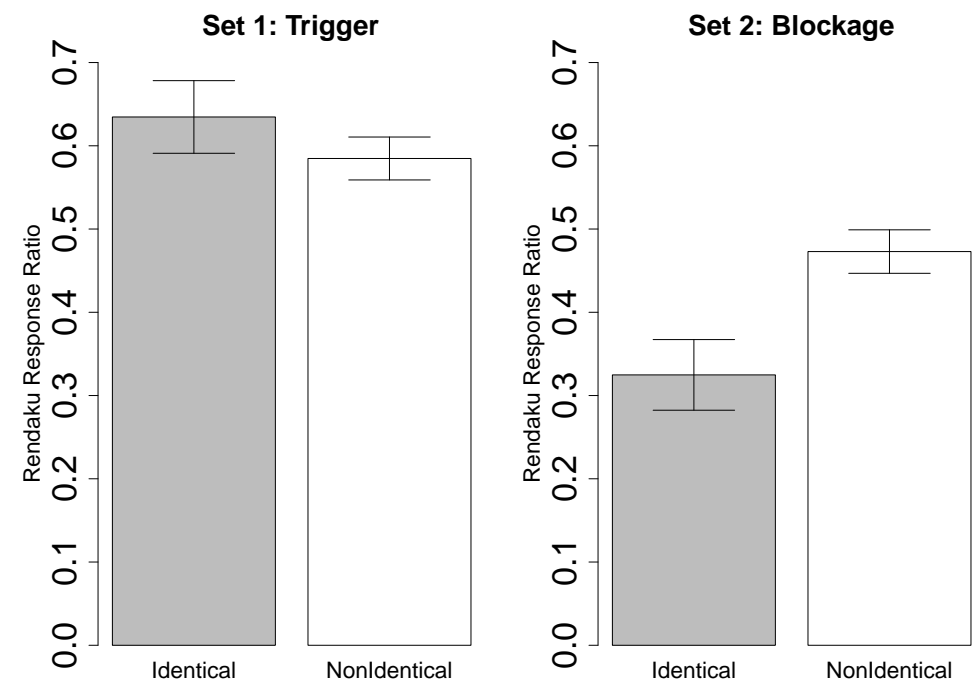

Figure 3: Comparing the results of Set 1 and Set 2.

These questions are related to yet another more general question of whether the Japanese (native) lexicon shows the same skew toward showing the effect of Identity Avoidance on rendaku and otherwise. Kawahara et al. (2006) showed some tendencies to avoid adjacent homorganic consonants in the native lexicon of Japanese, but to the best of our knowledge, there have been no studies on Identity Avoidance at the CV moraic level in the Japanese lexicon in general. Although more studies are warranted, it is unlikely that our current results are rooted in the statistical patterns in the Japanese lexicon—recall that Irwin (2013) finds no clear evidence of rendaku blockage due to Identity Avoidance in the existent pattern of rendaku.

We thus believe that it is likely that our results are an emergent effect of grammatical pressures (Identity Avoidance) in an experimental setting. To the best of our knowledge, the other aspects of our results have not been tested against the existing patterns of rendaku in the lexicon of contemporary Japanese. We can objectively address this question-whether the current results can be deduced from the patterns in the lexicon-once a comprehensive lexical database on rendaku is in place (see Irwin \& Miyashita 2013 for an on-going attempt to build a lexical database on rendaku). ${ }^{9}$

Finally, our experiment examined the identity avoidance at the moraic level (CV units), because CV units are important phonological units in Japanese prosodic organization (Itô, 1989; Kubozono, 1989; Labrune, 2012), and also because Sano (2013) found the effect of moraic identity avoidance in Japanese-(3a) and (3b) both violate consonantal identity avoidance, but only (3b) violates moraic identity avoidance. However, the current experimental results can also be interpreted as the effect of consonantal identity avoidance, a kind of the OCP effect that is more well known in Semitic languages (McCarthy, 1979). Yet again, it is necessary to run a follow up experiment to tease apart the two identity avoidance constraints in Japanese phonology. That follow-up experiment should include both moraic identity (as in [ika+kaniro]) and consonantal identity (as in [iki+kaniro]) to compare these factors.

obstruents are more marked than voiceless obstruents (Hayes \& Steriade, 2004). Given UCCRH—if *A $\gg * \mathrm{~B}$, then $* \mathrm{~A} \& * \mathrm{C} \gg * \mathrm{~B} \& * \mathrm{C}$, and given $*$ VoICEdOBS $\gg *$ VoICELESSOBS, then $*$ VoICEdOBS\&*VoICEDOBS $\gg$ $*$ VoicedObs $\& *$ VoicelessObs, and *VoICEdObs\&*VoicelessObs $\gg *$ VoicelessObs\&*VoicelessObs. By transitivity, *VoICEDOBS\&*VoICEDOBS $\gg *$ VoICELESSOBS\&*VoICELESSOBS.

9 The second author is addressing this issue using the Corpus of Spontaneous Japanese (Kokuritsu-Kokugo-Kenkyuujo, 2008) in an on-going study. 
4.3 Final Summary Our experiment has established the effect of Identity Avoidance on rendaku application. The study confirms the importance of output constraints in phonology in that they can both block and trigger the same phenomenon (i.e. conspiracy). The fact that this dual effect of Identity Avoidance on rendaku was not established until now, despite the fact that rendaku has been well studied, shows that experimentation is a useful approach to address phonological questions.

\section{References}

Berko, Jean (1958). The child's learning of English morphology. Word 14, 150-177.

Casali, Roderic (1996). Resolving Hiatus. Doctoral dissertation, University of California, Los Angeles.

Chomsky, Noam \& Moris Halle (1968). The Sound Pattern of English. Harper and Row, New York.

Fukuda, Suzy \& Shinji Fukuda (1994). To voice or not to voice: The operation of rendaku in the Japanese developmentally language-impaired. McGill Working Papers in Linguistics 10, 178-193.

Goldsmith, John (1994). Harmonic phonology. Goldsmith, John (ed.), The Last Phonological Rule, University of Chicago Press, Chicago, 21-60.

Hayes, Bruce \& Donca Steriade (2004). Introduction: The phonetic bases of phonological markedness. Hayes, Bruce, Robert Kirchner \& Donca Steriade (eds.), Phonetically Based Phonology., Cambridge University Press, Cambridge, $1-33$.

Inoue, Humio (1998). Nihongo Wocchingu [Watching Japanese]. Iwanami, Tokyo.

Irwin, Mark (2013). Rendaku and duplicate moras. Ms. Yamagata University.

Irwin, Mark \& Mizuki Miyashita (2013). The rendaku database v.2.0. Database.

Irwin, Mark (to appear). A rendaku bibliography. Vance, Timothy \& Mark Irwin (eds.), Perspectives on rendaku: Sequential voicing in Japanese compounds, Mouton, Berlin.

Itô, Junko (1989). A prosodic theory of epenthesis. Natural Language and Linguistic Theory 7, 217-259.

Itô, Junko \& Armin Mester (1986). The phonology of voicing in Japanese: Theoretical consequences for morphological accessibility. Linguistic Inquiry 17, 49-73.

Itô, Junko \& Armin Mester (2003). Japanese Morphophonemics. MIT Press, Cambridge.

Itô, Junko \& Armin Mester (2004). Morphological contrast and merger: Ranuki in Japanese. Journal of Japanese Linguistics 20, 1-19.

Jaeger, Florian T. (2008). Categorical data analysis: Away from ANOVAs (transformation or not) and towards logit mixed models. Journal of Memory and Language 59, 434-446.

Kawahara, Shigeto (2012). Lyman's Law is active in loanwords and nonce words: Evidence from naturalness judgment experiments. Lingua 122:11, 1193-1206.

Kawahara, Shigeto \& Shin-ichiro Sano (2013a). Identity avoidance and Lyman's Law. ms. Keio University and Okayama Prefectural University.

Kawahara, Shigeto \& Shin-ichiro Sano (2013b). Testing Rosen's Rule and Strong Lyman's Law. ms. Keio University and Okayama Prefectural University.

Kawahara, Shigeto (the lead author) (to appear). Experimental studies of rendaku. Vance, Timothy \& Mark Irwin (eds.), Perspectives on rendaku: Sequential voicing in Japanese compounds, Mouton, Berlin.

Kawahara, Shigeto, Hajime Ono \& Kiyoshi Sudo (2006). Consonant co-occurrence restrictions in Yamato Japanese. Vance, Timothy \& Kimberly Jones (eds.), Japanese/Korean Linguistics 14, CSLI, Stanford, vol. 14, 27-38.

Kindaichi, Haruhiko (1976). Rendaku-no kai [On explaining rendaku]. Sophia Linguistica 2, 1-22.

Kisseberth, Charles (1970). On the functional unity of phonological rules. Linguistic Inquiry 1, 291-306.

Kobayashi, Yuki, Yoko Sugioka \& Takane Ito (2013). Kisokutekiyoo toshite-no rendaku: Jishoo kanren den-i keisokujikken-no kekka-kara [Rendaku as rules: Evidence from an ERP experiment]. Talk presented at the 147th meeting of Linguistic Society of Japan.

Kokuritsu-Kokugo-Kenkyuujo (2008). Nihongo hanashikotoba koopasu [the Corpus of Spontaneous Japanese], ver. 2. Database.

Kubozono, Haruo (1989). The mora and syllable structure in Japanese: Evidence from speech errors. Language and Speech 32, 249-278.

Kubozono, Haruo (2005). Rendaku: Its domain and linguistic conditions. van der Weijer, Jeroen, Kensuke Nanjo \& Tetsuo Nishihara (eds.), Voicing in Japanese, Mouton de Gruyter, Berlin \& New York, 5-24.

Labrune, Laurence (2012). The phonology of Japanese. Oxford University Press, Oxford.

Leben, Will (1973). Suprasegmental Phonology. Doctoral dissertation, MIT.

Legendre, Géraldine, Yoshiro Miyata \& Paul Smolensky (1990). Harmonic grammar - a formal multi-level connectionist theory of linguistic well-formedness: Theoretical foundations. Proceedings of the Twelfth Annual Conference of the Cognitive Science Society, Lawrence Erlbaum Associates, Mahwah, NJ, 388-395.

Lyman, Benjamin S. (1894). Change from surd to sonant in Japanese compounds. Oriental Studies of the Oriental Club of Philadelphia 1-17. 
McCarthy, John J. (1979). Formal Problems in Semitic Phonology and Morphology. Doctoral dissertation, MIT. Published by Garland Press, New York, 1985.

McCarthy, John J. (1986). OCP effects: Gemination and antigemination. Linguistic Inquiry 17, 207-263.

McCarthy, John J. (2002). A Thematic Guide to Optimality Theory. Cambridge University Press, Cambridge.

McCawley, James D. (1968). The Phonological Component of a Grammar of Japanese. Mouton, The Hague.

Ohno, Kazutoshi (2000). The lexical nature of rendaku in Japanese. Nakayama, Mineharu \& Carles Quinn (eds.), Japanese/Korean Linguistics 9, CSLI Publications, Stanford, 151-164.

Okumura, Mitsuo (1984). Rendaku. Nihongogaku 3:5, 89-98.

Paradis, Carole (1988). On constraints and repair strategies. The Linguistic Review 6, 71-97.

Pater, Joe (1999). Austronesian nasal substitution and other NC effects. Kager, Rene, Harry van der Hulst \& Wim Zonneveld (eds.), The Prosody-Morphology Interface, Cambridge University Press, Cambridge, 310-343.

Prince, Alan \& Paul Smolensky (1993/2004). Optimality Theory: Constraint Interaction in Generative Grammar. Blackwell, Malden and Oxford [originally circulated in 1993 as ms. University of Colorado and Rutgers University].

Sano, Shin-ichiro (2013). Violable and inviolable OCP effects on linguistic changes: Evidence from verbal inflections in Japanese. Proceedings of FAJL 6 [MIT Working Papers in Linguistics 66] 145-156.

Sano, Shin-ichiro \& Shigeto Kawahara (2013). Testing rendaku experimentally: Rosen's Rule, (Strong) Lyman's Law and Identity Avoidance. Talk presented at ICPP 3.

Sato, H. (1988). Hukugougo-ni okeru akusento kisoku-to rendaku kisoku [Rules on compound accents and rendaku]. Nihongo no Onsei to On'in 2, 233-265.

Spaelti, Philip (1997). Dimensions of Variation in Multi-Pattern Reduplication. Doctoral dissertation, University of California, Santa Cruz.

Sugioka, Yoko (2002). Incorporation vs. modification in deverbal compounds. Akatsuka, Noriko \& Susan Strauss (eds.), Japanese/Korean Linguistics 10, CSLI Publications, Stanford, 495-508.

Sugioka, Yoko (2005). Multiple mechanisms underlying morphological productivity. Mufwene, Salikoko S., Elaine J. Francis \& Rebecca S. Wheeler (eds.), Polymorphous Linguistics: Jim McCawley's Legacy, MIT Press, Cambridge, 204-223.

Sugito, Miyoko (1965). Shibata-san to Imada-san: Tango-no chookakuteki benbetsu-no ichi koosatsu [Mr. Satoo and Mr. Imada: An analysis of auditory distinction of words]. Gengo Seikatsu 165.

Ueda, Kazutoshi (1898). P-onkoo [On the sound P]. Teikoku Bungaku [National Literature] 4:1. Reprinted in Kokugo no Tame [For Japanese Linguistics]. Fujishoboo. pp. 32-39.

Unger, Marshall (1975). Studies in Early Japanese Morphophonemics. Doctoral dissertation, Yale University.

Vance, Timothy J. (2007). Have we learned anything about rendaku that Lyman didn't already know? Frellesvig, Bjarke, Masayoshi Shibatani \& John Carles Smith (eds.), Current issues in the history and structure of Japanese, Kurosio, Tokyo, 153-170.

Vance, Timothy J. (to appear). Rendaku. Kubozono, Haruo (ed.), The Handbook of Japanese Language and Linguistics: Phonetics and Phonology, Mouton, Gruyter.

Yip, Moira (1988). The Obligatory Contour Principle and phonological rules: A loss of identity. Linguistic Inquiry 19, 65-100.

Yip, Moira (1995). Repetition and its avoidance: The case of Javanese. Suzuki, Keiichiro \& Dirk Elzinga (eds.), Proceedings of South Western Optimality Theory Workshop 1995, The Linguistics Circle and the Department of Linguistics at the University of Arizona, Tuscon, 238-262.

Yip, Moira (1998). Identity avoidance in phonology and morphology. Lapointe, Steven G., Diane K. Brentari \& Patrick M. Farrell (eds.), Morphology and its Relation to Phonology and Syntax, CSLI Publications, Stanford, 216-246.

Zuraw, Kie \& Yu-An Lu (2009). Diverse repairs for multiple labial consonants. Natural Language and Linguistic Theory 27:1, 197-224. 